\title{
28 Research Square \\ Brno University of Technology ECG Signal Database with Annotations of P Wave (BUT PDB)
}

\section{Lucie Maršánová ( $\nabla$ marsanova@vut.cz)}

Brno University of Technology: Vysoke uceni technicke v Brne https://orcid.org/0000-0003-1638-4814

\section{Radovan Smíšek}

Brno University of Technology: Vysoke uceni technicke v Brne

\section{Andrea Němcová}

Brno University of Technology: Vysoke uceni technicke v Brne

\section{Lukáš Smital}

Brno University of Technology: Vysoke uceni technicke v Brne

\section{Martin Vítek}

Brno University of Technology: Vysoke uceni technicke v Brne

\section{Short report}

Keywords: ECG Signal Database, Biomedical Engineering

Posted Date: October 5th, 2021

DOI: https://doi.org/10.21203/rs.3.rs-942006/v1

License: (c) (1) This work is licensed under a Creative Commons Attribution 4.0 International License. Read Full License 


\section{Abstract}

Background: Brno University of Technology ECG Signal Database with Annotations of P Wave (BUT PDB) is an ECG signal database with marked peaks of $P$ waves created by the cardiology team at the Department of Biomedical Engineering, Brno University of Technology.

Results: The database consists of 50 2-minute 2-lead ECG signal records with various types of pathologies. The ECGs were selected from 3 existing databases of ECG signal - MIT-BIH Arrhythmia Database, MIT-BIH Supraventricular Arrhythmia Database and Long Term AF Database. The P waves positions were manually annotated by two ECG experts in all 50 records. Each record contains also dominant diagnosis (pathology) present in the record and annotated positions and types of QRS complexes (from the original database).

Conclusion: The database is created for the development, evaluation and objective comparison of $\mathrm{P}$ wave detection algorithms.

\section{Introduction}

Electrocardiography (ECG) is nowadays still the most available and widely used method for the cardiovascular system examination [1]. ECG signal reflects the electrical activity of the heart and provides a significant amount of information about the heart function [2]. Accurate detection of ECG components, such as P wave, QRS complex and T wave are fundamental steps of ECG analysis and subsequent cardiac pathological events detection. In practice, automated evaluation of ECG records using software is necessary [3]. The detection of QRS complexes and T waves is usually efficient. However, methods for $P$ wave detection are not so successful in physiological signals and especially in pathological signals. It applies both in real practise and research [4],[5],[6],[7].

One of the reasons that prevents the progress in this field is a lack of publicly available datasets with correct $\mathrm{P}$ waves annotations suitable for training and testing of detection algorithms [5],[8].

The methods are usually tested only on a part of publicly available QT database [9],[10] or on a not publicly available CSE database [11], both with manual $P$ waves annotations. In addition to this, there are two new databases, namely MIT-BIH Arrhythmia Database P-Wave Annotations [5],[9],[12] and Lobachevsky University Electrocardiography Database [9],[6], whose use is not frequent yet. There are also two publicly available databases with $P$ waves annotations which contain mistakes - $P$ waves annotations of MIT-BIH Arrhythmia database by Elgendi et al. [13] and automatically annotated part of QT database [10]. Thus, these annotations cannot be recommended to be used for testing of $P$ wave detection algorithms.

The most commonly used databases, QT database and CSE database contain predominantly physiological ECG records, or contain only those pathologies which do not affect $P$ wave detection. However, the content of the pathologies in databases is very important for objective testing of $\mathrm{P}$ wave 
detection algorithms. During the pathological function of the heart, the information about the positions of the $P$ waves is very important for determining the diagnosis. Unfortunately, current algorithms are not able to detect $P$ waves in pathological signals reliably.

Therefore, we fill this gap and introduce a new database of ECG signals with manually annotated $P$ waves. The Brno University of Technology ECG Signal Database with Annotations of P Wave (BUT PDB) database consists of 50 2-minute 2-lead ECG signals with 23 types of pathologies. The P waves positions were manually annotated by two ECG experts with 7 years of practical experiences with evaluation of holter ECG records in cardiovascular ambulance [5]. The database will help to develop new, more accurate, and robust methods for processing and analysing ECG records in the sense of $P$ wave detection.

\section{Materials And Methods Selection of data}

The ECG signals were selected by two ECG experts from 3 existing databases of ECG signals - from MITBIH Arrhythmia Database (MIT-A) [9],[14], MIT-BIH Supraventricular Arrhythmia (MIT-S) Database [9],[15] and Long Term AF Database (LT-AF) [9],[16]. All the databases contain ECG signals and annotations of positions and types of QRS complexes. The MIT-A database additionally contains annotations of types of arrhythmias present in records. The detailed information about these databases is available on Physionet [9] or in the articles [14],[15],[16].

Two ECG experts went through the records and selected interesting two-minute sections with higher incidence of pathologies during which it is usually difficult to detect $\mathrm{P}$ waves by automatic algorithms. The signals were chosen to represent as many types of pathologies present in records in real medical practice as possible.

The final database consists of 50 2-minute 2-lead ECG signals with various types of pathologies. The whole database contains 23 different types of pathologies. The amount and type of pathologies is chosen to represent a real sample of data from medical practice. From MIT-A database, 38 signals were selected. From MIT-S database, 5 signals were selected. From LT-AF database, 7 signals were selected. The BUT PDB includes 7,638 QRS complexes of which 2,120 are without P wave (e.g. atrial fibrillation, ventricular beats or during nodal rhythm) and $81 \mathrm{P}$ waves are without QRS complex (e.g. 2nd degree atrioventricular block). Altogether, the BUT PDB includes 5,599 P waves. In the BUT PDB, 23 different types of pathologies are present. Types of pathologies with their abbreviations used in the BUT PDB, number of cases (records) and IDs of the records in which the pathology is present are listed in Table 1.

\section{Annotation Of Data}


The $\mathrm{P}$ waves positions were manually annotated by two ECG experts with 7 years of practical experiences with evaluation of holter ECG records in cardiovascular ambulance [18], [5]. The first expert provided manual annotations, and the second manually checked them. Unclear parts of the records were discussed by both experts until a consensus was reached. Everything was conducted manually without the use of automated annotating software. To facilitate the work of ECG experts, a free software tool, SignalPlant [17], was used for manual marking of $P$ waves. The experts worked independently. Unclear parts of the records were discussed by both experts until a consensus was reached. The selected records are interesting two-minute sections with higher incidence of pathologies during which it is usually difficult to detect $P$ waves by automatic algorithms. 
Table 1

Types of pathologies with their abbreviations used in the BUT PDB, number of cases (records) and IDs of the records in which the pathology is present.

\begin{tabular}{|c|c|c|c|}
\hline Abb. & Type of pathology & Number of cases & $\begin{array}{l}\text { IDs of the records } \\
\text { with the pathology }\end{array}$ \\
\hline A & Atrial premature beat & 14 & $\begin{array}{l}04,05,09,16,17,18,26 \\
28,35,38,39,40,41,43\end{array}$ \\
\hline AFIB & Atrial fibrillation & 9 & $07,08,44,45,46,47,48,49,50$ \\
\hline AFL & Atrial flutter & 2 & 08,38 \\
\hline B & Ventricular bigeminy & 3 & $02,14,27$ \\
\hline $\mathrm{BI}$ & 1st degree atrioventricular block & 1 & 22 \\
\hline BII & 2nd degree atrioventricular block & 2 & 01,13 \\
\hline BIII & 3rd degree atrioventricular block & 1 & 03 \\
\hline $\mathrm{E}$ & Ventricular escape beat & 1 & 09 \\
\hline $\mathrm{F}$ & Fusion beat & 3 & $30,31,32$ \\
\hline IVR & Idioventricular rhythm & 1 & 30 \\
\hline$J$ & Nodal beat & 3 & $06,07,15$ \\
\hline L & Left bundle branch block beat & 4 & $21,22,36,41$ \\
\hline NA & Sinus arrhythmia & 1 & 24 \\
\hline NOD & Nodal rhythm & 3 & $06,07,15$ \\
\hline$P$ & Paced rhythm & 2 & 03,19 \\
\hline PREX & Pre-excitation & 1 & 12 \\
\hline $\mathrm{R}$ & Right bundle branch block beat & 4 & $01,13,26,34$ \\
\hline SVTA & Supraventricular tachyarrhythmia & 3 & $09,11,43$ \\
\hline $\mathrm{T}$ & Ventricular trigeminy & 2 & 27,29 \\
\hline V & Ventricular premature beat & 20 & $\begin{array}{l}05,10,14,19,20,21,25,27,28,29,30, \\
31,32,33,35,36,39,40,41,42\end{array}$ \\
\hline VFL & Ventricular flutter & 1 & 33 \\
\hline VP & Ventricular pair & 1 & 25 \\
\hline a & Aberrated atrial premature beat & 1 & 23 \\
\hline
\end{tabular}


Each record also contains annotation of dominant diagnosis (pathology) and types of QRS complexes (from the original databases) [9],[14]. The information of pathologies present in records was checked (the original annotations were found correct) and taken over from the original databases and supplemented by ECG experts in the cases where the information was missing (all signals from MIT-S). The information about types of QRS complexes is taken over from the original databases.

\section{Results And Discussion}

The final database contains 23 different types of pathologies. The amount and type of pathologies is chosen to represent a real sample of data from medical practice.

In Table 2, information about each record from BUT PDB is listed. The information contains: IDs of the record, types of pathologies present in each record, original database, IDs of the record from the original database and the start and the end (in samples) of the selected segment. 
Table 2

Information about each record from BUT PDB: IDs of the record, types of pathologies present in each record, original database, IDs of the record from the original database, the start and the end (in samples) of the selected segment and sampling frequency of the record.

\begin{tabular}{|c|c|c|c|c|c|}
\hline $\begin{array}{l}\text { IDs of } \\
\text { the } \\
\text { record }\end{array}$ & $\begin{array}{l}\text { Types of } \\
\text { pathologies }\end{array}$ & Database & $\begin{array}{l}\text { Original name } \\
\text { of the record }\end{array}$ & $\begin{array}{l}\text { The start and the end of } \\
\text { the segment [samples] }\end{array}$ & $\begin{array}{l}\text { Sampling } \\
\text { frequency } \\
{[\mathrm{Hz}]}\end{array}$ \\
\hline 01 & 'BII, R' & MIT-A & 231 & {$[30160,73360]$} & 360 \\
\hline 02 & 'V, B' & MIT-A & 106 & {$[34920,78120]$} & 360 \\
\hline 03 & 'BIII' & MIT-A & 107 & {$[266400,309600]$} & 360 \\
\hline 04 & 'A' & MIT-A & 108 & {$[525600,568800]$} & 360 \\
\hline 05 & 'A, V' & MIT-A & 118 & {$[486720,529920]$} & 360 \\
\hline 06 & 'NOD, J' & MIT-A & 124 & {$[104400,147600]$} & 360 \\
\hline 07 & $\begin{array}{l}\text { 'AFIB, NOD, } \\
\text { J' }\end{array}$ & MIT-A & 201 & {$[124200,167400]$} & 360 \\
\hline 08 & 'AFIB, AFL' & MIT-A & 203 & {$[572400,615600]$} & 360 \\
\hline 09 & 'E, A, SVTA' & MIT-A & 207 & {$[594000,637200]$} & 360 \\
\hline 10 & 'V, T' & MIT-A & 208 & {$[414000,457200]$} & 360 \\
\hline 11 & 'SVTA' & MIT-A & 209 & {$[518400,561600]$} & 360 \\
\hline 12 & 'PREX' & MIT-A & 230 & {$[108000,151200]$} & 360 \\
\hline 13 & 'BII, R' & MIT-A & 231 & {$[478800,522000]$} & 360 \\
\hline 14 & 'V, B' & MIT-A & 233 & [201960,245160] & 360 \\
\hline 15 & 'J' & MIT-A & 234 & [288360,331560] & 360 \\
\hline 16 & 'A' & MIT-A & 101 & {$[439560,482760]$} & 360 \\
\hline 17 & 'A' & MIT-A & 112 & [248400,291600] & 360 \\
\hline 18 & 'A' & MIT-A & 114 & {$[439560,482760]$} & 360 \\
\hline 19 & 'P, F, V' & MIT-A & 104 & {$[576000,619200]$} & 360 \\
\hline 20 & 'V' & MIT-A & 105 & {$[572400,615600]$} & 360 \\
\hline 21 & 'L, V' & MIT-A & 109 & {$[601200,644400]$} & 360 \\
\hline 22 & 'L, Bl' & MIT-A & 111 & [169200,212400] & 360 \\
\hline 23 & 'a' & MIT-A & 113 & {$[478800,522000]$} & 360 \\
\hline 24 & 'NA' & MIT-A & 115 & {$[541800,585000]$} & 360 \\
\hline
\end{tabular}




\begin{tabular}{|c|c|c|c|c|c|}
\hline $\begin{array}{l}\text { IDs of } \\
\text { the } \\
\text { record }\end{array}$ & $\begin{array}{l}\text { Types of } \\
\text { pathologies }\end{array}$ & Database & $\begin{array}{l}\text { Original name } \\
\text { of the record }\end{array}$ & $\begin{array}{l}\text { The start and the end of } \\
\text { the segment [samples] }\end{array}$ & $\begin{array}{l}\text { Sampling } \\
\text { frequency } \\
{[\mathrm{Hz}]}\end{array}$ \\
\hline 25 & 'V, VP' & MIT-A & 116 & {$[550800,594000]$} & 360 \\
\hline 26 & 'R, A' & MIT-A & 118 & {$[478800,522000]$} & 360 \\
\hline 27 & 'V, B, T' & MIT-A & 119 & {$[97200,140400]$} & 360 \\
\hline 28 & 'A, V' & MIT-A & 121 & [356400,399600] & 360 \\
\hline 29 & 'V' & MIT-A & 123 & {$[540000,583200]$} & 360 \\
\hline 30 & $\begin{array}{l}\text { 'P, IVR, T, V, } \\
\mathrm{F}^{\prime}\end{array}$ & MIT-A & 124 & {$[367200,410400]$} & 360 \\
\hline 31 & 'V, F, VT' & MIT-A & 205 & [522000,565200] & 360 \\
\hline 32 & 'V, F, VT' & MIT-A & 205 & {$[91440,134640]$} & 360 \\
\hline 33 & 'V, VFL, ' & MIT-A & 207 & {$[55440,98640]$} & 360 \\
\hline 34 & 'R' & MIT-A & 212 & {$[518400,561600]$} & 360 \\
\hline 35 & 'V, A' & MIT-A & 213 & [529200,572400] & 360 \\
\hline 36 & 'V, L' & MIT-A & 214 & {$[583200,626400]$} & 360 \\
\hline 37 & 'A, FIB' & MIT-A & 219 & {$[410400,453600]$} & 360 \\
\hline 38 & $\begin{array}{l}\text { 'NOD, AFL, } \\
A^{\prime}\end{array}$ & MIT-A & 222 & {$[475200,518400]$} & 360 \\
\hline 39 & 'V, A' & MIT-S & 801 & {$[26570,41929]$} & 128 \\
\hline 40 & 'V, A' & MIT-S & 802 & [181220,196579] & 128 \\
\hline 41 & 'L, A, V' & MIT-S & 886 & [202320,217679] & 128 \\
\hline 42 & 'V' & MIT-S & 851 & {$[150320,165679]$} & 128 \\
\hline 43 & 'A, SVTA' & MIT-S & 811 & [196820,212179] & 128 \\
\hline 44 & 'AFIB' & LT-AF & 101 & [3865673,3881032] & 128 \\
\hline 45 & 'AFIB' & LT-AF & 120 & [321823,337182] & 128 \\
\hline 46 & 'AFIB' & LT-AF & 55 & [10002594,10017953] & 128 \\
\hline 47 & 'AFIB' & LT-AF & 56 & {$[5229657,5245016]$} & 128 \\
\hline 48 & 'AFIB' & LT-AF & 62 & [8495932,8511291] & 128 \\
\hline 49 & 'AFIB' & LT-AF & 102 & [10683803,10699162] & 128 \\
\hline 50 & 'AFIB' & LT-AF & 117 & {$[4050966,4066325]$} & 128 \\
\hline
\end{tabular}


The examples of records with various pathologies (ie. 2nd atrioventricular block (rec. 01), ventricular premature contraction, ventricular tachycardia, atrial fibrillation (rec. 48)) and newly annotated $\mathrm{P}$ waves are shown in Fig. 1.

The BUT PDB is available on Physionet [9],[19]. All data are provided in the WaveForm Database (WFDB) format, which is supported by the WFDB Software Package [9]. The IDs of the recordings are numbers from 01 to 50. The ECG signals are stored in files with suffix *.dat, the annotations of $P$ waves are in stored files with suffix *.pwave, the positions of QRS complexes, their types and sampling frequency of each ECG signal are stored in files with suffix *.qrs. The exact types of pathologies present in each signal are described in the text file with the name README.txt.

The codes needed for the loading of data are available on Physionet [9] https://archive.physionet.org/physiotools/wfdb.shtml). In case of using Matlab, for loading files *.dat with ECG records use function "rdsamp" (eg. [signal, fs, tm] = rdsamp ('17.dat')), for loading files with annotations of $\mathrm{P}$ waves or QRS complexes and their types use function 'rdann' (eg. [P] = rdann ('17', 'pwave') or [QRS, typeQRS] = rdann('17', 'qrs')).

\section{Conclusions}

BUT PDB is created for the development, testing and objective comparison of algorithms for $P$ waves detection. For objective comparison, the prerequisite is that they will use the entire database and that they will not select and/or shorten the signals. The database includes a representative sample of pathologies present in records in real medical practice. If the algorithms will be reliably able to deal with $\mathrm{P}$ waves detection in all types of pathologies present in this database, they will be usable for implementation to the software for ECG signals analysis in real medical practice.

\section{Declarations}

\section{Data Availability}

The BUT PDB is publicly available on Physionet [9],[19].

\section{Conflicts of Interest}

There are no conflicts of interest..

\section{Funding Statement}

This work has been funded by the United States Office of Naval Research (ONR) Global, award number N62909-19-1-2006. 


\section{Acknowledgments}

The authors wish to thank LCDR Joshua Swift from ONR Code 342 and Dr. Stephen O'Regan from ONR Global Central and Eastern European Office for their support. The funders had no role in the design of the study; in the collection, analyses, or interpretation of data; in the writing of the manuscript, or in the decision to publish the results.

\section{References}

1. World Health Organization. "Cardiovascular Diseases," Available from: https://www.who.int/healthtopics/cardiovascular-diseases\#tab=tab_1.

2. Mendis S, et al. "Global atlas on cardiovascular disease prevention and control, " World Health Organization, 2011.

3. Wagner GS, et al. "AHA/ACCF/HRS Recommendations for the Standardization and Interpretation of the Electrocardiogram". J Am Coll Cardiol. 2009;53:1003-11.

4. Portet FP, et al. "P wave detector with PP rhythm tracking: evaluation in different arrhythmia contexts. "Physiological Measurement. 2008;29:141-55.

5. Maršánová L, et al. "Advanced P Wave Detection in Ecg Signals During Pathology: Evaluation in Different Arrhythmia Contexts," Scientific Reports, vol. 9, 2019.

6. Kalyakulina Al, et al. "LUDB: A New Open-Access Validation Tool for Electrocardiogram Delineation Algorithms," IEEE Access, vol. 8, 2020.

7. Hossain MB, et al. "An Accurate QRS Complex and P Wave Detection in ECG Signals Using Complete Ensemble Empirical Mode Decomposition with Adaptive Noise Approach“ IEEE Access, vol. 7, 2019.

8. Leutheuser $\mathrm{H}$, et al. "Instantaneous P- and T-wave detection: Assessment of three ECG fiducial points detection algorithms," 2016 IEEE 13th International Conference on Wearable and Implantable Body Sensor Networks, pp. 329-334, 2016.

9. Goldberger AL, et al. "PhysioBank, PhysioToolkit, and PhysioNet," Circulation, 2000.

10. Laguna P, et al. B. "A database for evaluation of algorithms for measurement of QT and other waveform intervals in the ECG," Computers in Cardiology 1997, pp. 673-676, 1997.

11. Willems JL, et al. "Common Standards for Quantitative Electrocardiography" Journal of Electrocardiology, vol. 21, pp. 209-217.

12. Maršánová L, et al. "Automatic Detection of P Wave in ECG During Ventricular Extrasystoles," World Congress on Medical Physics and Biomedical Engineering 2018, pp. 381-385, 2019.

13. Elgendi M, et al. "A Proof-of-Concept Study: Simple and Effective Detection of P and T Waves in Arrhythmic ECG Signals," Bioengineering, vol. 3, 2016.

14. Moody GB, et al. "The impact of the MIT-BIH Arrhythmia Database," IEEE Engineering in Medicine and Biology Magazine, vol. 20, pp. 45-50. 
15. Greenwald SD, et al. "Improved detection and classification of arrhythmias in noise-corrupted electrocardiograms using contextual information," Proceedings Computers in Cardiology, pp. 461464, 1991.

16. Petrutiu S, et al. "Abrupt changes in fibrillatory wave characteristics at the termination of paroxysmal atrial fibrillation in humans," EP Europace, vol. 9, pp. 466-470, 2007.

17. Plesinger F, et al. "SignalPlant: an open signal processing software platform," Physiological Measurement, vol. 37, pp. 38-48, 2016.

18. Smíšek R, et al. "CSE database: extended annotations and new recommendations for ECG software testing," Medical and Biological Engineering and Computing, vol. 8, pp. 1473-1482, 2017.

19. Maršánová L, et al. "Brno University of Technology ECG Signal Database with Annotations of P Wave (BUT PDB)," PhysioNet, 2021.

\section{Figures}
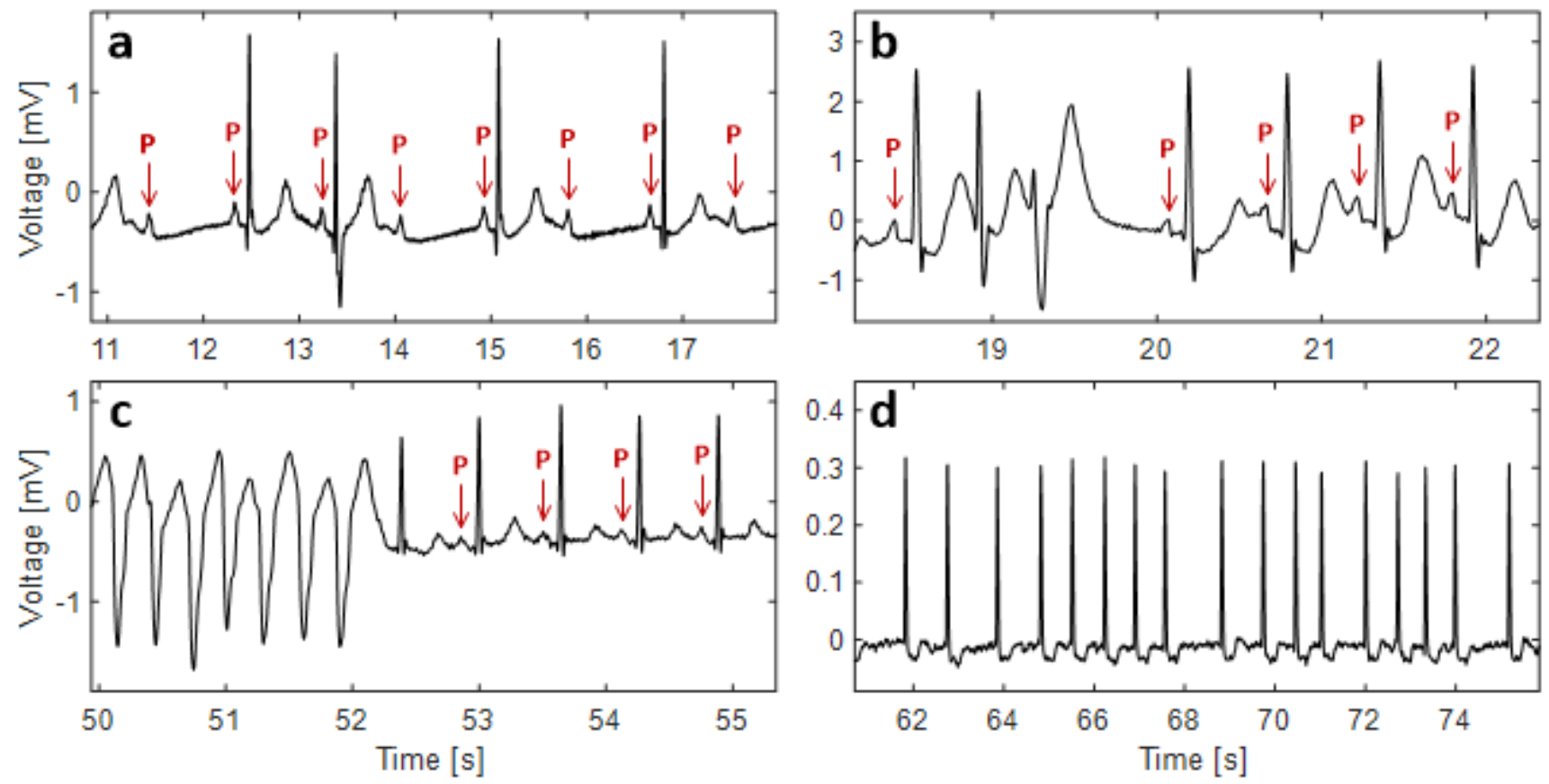

Figure 1

The examples of records with annotated P waves. Subgraph a) 2nd atrioventricular block (rec. 01) b) ventricular premature contraction (rec. 35), c) ventricular tachycardia (rec. 32) and d) atrial fibrillation (rec. 48). 